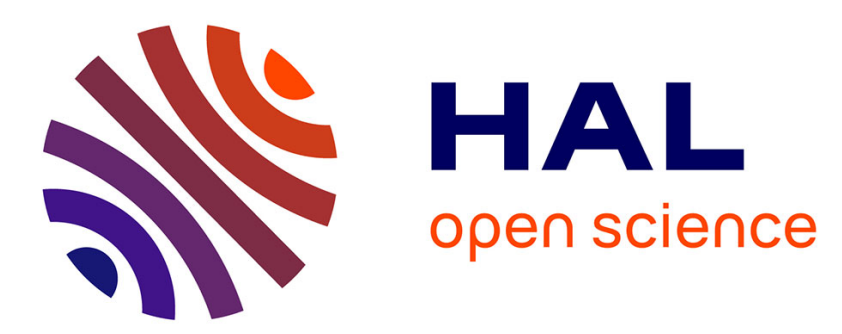

\title{
Intra-articular nodular fasciitis of the proximal interphalangeal joint of a finger: A case report
}

H. Choughri, J.-M. Coindre, F.M. Leclère

\section{To cite this version:}

H. Choughri, J.-M. Coindre, F.M. Leclère. Intra-articular nodular fasciitis of the proximal interphalangeal joint of a finger: A case report. Hand Surgery and Rehabilitation, 2019, 38, pp.74 - 78. 10.1016/j.hansur.2018.09.004 . hal-03486609

\section{HAL Id: hal-03486609 \\ https://hal.science/hal-03486609}

Submitted on 20 Dec 2021

HAL is a multi-disciplinary open access archive for the deposit and dissemination of scientific research documents, whether they are published or not. The documents may come from teaching and research institutions in France or abroad, or from public or private research centers.
L'archive ouverte pluridisciplinaire HAL, est destinée au dépôt et à la diffusion de documents scientifiques de niveau recherche, publiés ou non, émanant des établissements d'enseignement et de recherche français ou étrangers, des laboratoires publics ou privés.

\section{다)(1) $(5$}

Distributed under a Creative Commons Attribution - NonCommerciall 4.0 International 
Intra-articular nodular fasciitis of the proximal interphalangeal joint of a finger: A case report

Fasciite nodulaire de l'articulation interphalangienne proximale d'un doigt : à propos d'un cas

H. Choughri ${ }^{1}$, J.-M. Coindre ${ }^{2}$, FM. Leclère ${ }^{1}$

1 : Service de chirurgie plastique, reconstructrice et esthétique-Brûlés- Chirurgie de la Main, CHU de Bordeaux-Groupe hospitalier Pellegrin, Centre François-Xavier Michelet, Place AmélieRaba-Léon, 33076 Bordeaux cedex, France

2 : Institut Bergonié, Département de Pathologie-Cancérologie, Université de Bordeaux, 229, cours de l'Argonne, 33000 Bordeaux, France

\section{Corresponding author:}

Docteur Hussein Choughri, praticien hospitalier

Centre François-Xavier-Michelet, service de chirurgie plastique et main, groupe hospitalier Pellegrin, place Amélie-Raba-Léon, 33076 Bordeaux cedex, France

tel $+33(06) \cdot 88 \cdot 00 \cdot 02 \cdot 80$

$\operatorname{fax}+33(05) \cdot 57 \cdot 82 \cdot 05 \cdot 04$

choughrih@yahoo.fr

\section{Autres auteurs:}

Jean-Michel Coindre

Franck-Marie Leclère 
Conflit d'intérêt :

Aucun des auteurs ne présente de conflit d'intérêt (No conflit of interest). 
Intra-articular nodular fasciitis of the proximal interphalangeal joint of a finger: A case report

\title{
Fasciite nodulaire de l'articulation interphalangienne proximale d'un doigt : à propos d'un cas
}

\begin{abstract}
Nodular fasciitis is a benign reactive lesion, often mistaken for a soft tissue sarcoma in clinical practice. Involvement of the finger is rare, and a finger joint even rarer. We report on the clinical, radiological and histological features of intra-articular nodular fasciitis in a 52year-old man, originating from the proximal interphalangeal joint of the right ring finger, with cortical erosion of adjacent bone. The discussion is focused on the tumor diagnosis and therapeutic approach, the differential diagnosis and the importance of immunohistochemical staining to establish the final diagnosis.
\end{abstract}

\section{Résumé}

La fasciite nodulaire est une lésion réactive bénigne, souvent confondue avec un sarcome des tissus mous dans notre pratique clinique. La localisation au doigt est rare, et en regard d'une articulation de doigt encore plus rare. Nous rapportons les caractéristiques cliniques, radiologiques et histologiques d'une fasciite nodulaire intra-articulaire chez un homme de 52 ans, localisée à l'articulation interphalangienne proximale de l'annulaire droit, et associée à une érosion corticale de l'os sous-jacent. La discussion s'est portée sur l'approche diagnostique et thérapeutique de la tumeur, le diagnostic différentiel et l'importance des marquages immunohistochimiques afin d'établir le diagnostic final.

Key words: Articular nodular fasciitis; Finger; Tumor; Cortical erosion; Immunohistochemistry Mots clés : Fasciite nodulaire articulaire ; Doigt ; Tumeur ; Erosion corticale ; Immunohistochimie 


\section{Introduction}

Nodular fasciitis (NF) is a well-known benign, reactive myofibroblastic proliferation, with aggressive histological appearance, which is characterized clinically by a history of a rapidly growing single subcutaneous mass (over a few weeks) that may be mistaken for a sarcoma [1-3]. Here we present a rare case of NF, located under the volar plate of the proximal interphalangeal (PIP) joint of a finger, which caused erosion of the cortical surface of the base of the middle phalanx and the neck of the proximal phalanx. The initial biopsy did not lead to a precise diagnosis but helped to rule out a neoplastic process. Histological differential diagnosis included a desmoid tumor (DT), NF and fibroma of the tendon sheath (FTS). Finally, complete excision of the tumor confirmed the diagnosis of NF after several immunohistochemical stains were done. Our discussion is focused on the treatment approach, the differential diagnosis and the importance of immunohistochemical staining to establish the final diagnosis. The patient was informed that data concerning this case would be submitted for publication and provided his consent.

\section{Case report}

A 54-year-old right-handed man who worked as a general practitioner, was referred to our outpatient clinic with 3-month history of a swollen painful ring finger of his dominant (right) hand, with limited flexion of his proximal interphalangeal (PIP) joint. The story began when he experienced spontaneous discomfort including pain and swelling, without any notion of trauma. As general practitioner, the patient decided to treat himself with non-steroidal antiinflammatory drugs during a few weeks, thinking it was simply a finger sprain. He had temporary improvement, with partial regression of edema and slight improvement in PIP mobility. Faced with persistent symptoms, the patient requested a finger X-ray (Fig.1A), which was normal. One month later, he requested an appointment with a rheumatologist who did a blood test, another set of plain X-rays and an ultrasound of the finger. The blood test was normal. Ultrasound examination revealed PIP joint effusion with osteoarthritis. In comparison with the first set of normal X-rays, the second set of X-rays (Fig.1B) showed a 
well-defined cortical erosion at the base of the middle phalanx and the neck of the proximal phalanx. Two joint aspirations were performed with one week under ultrasound guidance and found no liquid. A magnetic resonance imaging (MRI) scan was performed next which showed a nonspecific, well-circumscribed mass, $2.2 \times 1.5 \times 0.8 \mathrm{~cm}$ in size, that was isointense on T1-weighted images and had heterogeneous high signal intensity on T2weighted images (Fig.1C and D).

The patient was referred to us 3 months after the initial onset. He had a history of a traumatic spiral fracture of the middle phalanx of his finger 10 years ago, treated with a cast. Physical examination showed a painful right ring finger, with local swelling and deficit in the of the PIP joint range of motion (ROM) $\left(-10^{\circ}+60^{\circ}\right.$ versus $0-80^{\circ}$ over the contralateral side). There was no triggering, sensory disturbance or joint instability. No palpable mass was identified, and the joint was not warm to touch. With the presumptive diagnosis of a nonspecific soft tissue tumor on MRI including the possibility of a sarcoma, an ultrasoundguided biopsy was performed to obtain the definitive diagnosis needed before surgery.

Histopathological examination ruled out any malignant tumor proliferation process, evoking a benign myofibroblastic fibrous lesion with spindle-shaped cells in a loosely textured myxoid matrix and wide bands of collagen, suggestive of a fibrous tumor. The differential diagnosis included NF, FTD and DT.

Given the patient's pain, continued rapid growth of the lesion radiologically with cortical bone erosion, size of the tumor, PIP joint location under the volar plate, and a benign histological diagnosis of a fibrous tumor, surgical excision was decided to ensure complete removal of the mass after discussion in a multidisciplinary cancer team meeting. This was performed through a volar surgical approach using a Bruner incision with release of the A2, A3 and A4 pulleys, tendon dislocation, and complete detachment of the volar plate (Fig. 2A, B).

Histological examination of the surgical specimen (Fig.3 A, B) revealed a nonencapsulated tumor composed of cytologically bland plump spindle cells arranged in short, intersecting bundles within a variable loose myxoid to collagenous stroma, containing 
extravagated red bloods cells and scattered lymphocytes. The lesion also showed prominent stromal development. Immunohistochemistry $(\mathrm{IHC})$ staining revealed the spindle cells were positive for alpha-smooth muscle actin (SMA, 1A4, 1:100; DAKO) and Ki67 (MIB-1, 1:150; DAKO), with an MIB-1 proliferation index of around 15\%. It was negative for beta-catenin (Beta-catenin-1, 1:100; DAKO), S-100 protein (Polyclonal, 1:3000, DAKO), CD34 (Qbend10, 1:100, novocastra), HMGA2 (High Mobility Group AT-Hook 2), cytokeratin (AE1-AE3, 1:100, DAKO), EMA (E29, 1:200, DAKO), caldesmon (h-CD; 1:100, DAKO) and desmin (D33,1:100; DAKO). From these findings, the diagnosis of DT was ruled out and a diagnosis of FTS proposed. This was finally changed to NF after considering all the IHC results and specifically the USP6 Break-Apart FISH probe results which confirmed rearrangement in $28 \%$ of the cells analyzed.

\section{Discussion}

Nodular fasciitis was first described by Konwaler et al. [4] in 1995 and called pseudosarcomatous fibromatosis because of its rapid growth and histologic presentation. It is often misdiagnosed as a malignant neoplasm (fibrosarcoma or malignant fibrous histiocytoma) in clinical practice. The etiology of NF is still unclear. NF is known to be a benign version of sarcoma, both clinically and histologically. It typically develops in the upper limbs (46\%), especially the volar aspect of the forearm followed by the head and neck (20\%), trunk (18\%), and lower extremities (16\%) [5]. NF can be divided into 3 major subtypes: subcutaneous, intramuscular, and fascial; it is often located in the subcutaneous tissue. AlQattan and Arafah reported four cases of NF of the hand treated surgically over a 20-year period. They preserved vital structures such digital nerve, both digital arteries of a finger, the volar plate, and the flexor profundus tendon; none of these tumors had joint involvement [6]. NF has also been reported in other unusual anatomical locations such as the parotid gland and urinary bladder or at the cubital fossa [7]. NF is extremely rare in the hand, and less than 30 cases have been reported in the literature. Of these rare sites, plus the rare location in the hand, the joint is one addition. Cortical erosion associated with NF in the hand has rarely 
been described [8]. To date, there are 19 cases of intraarticular NF reported. Of these, 13 were in the knee, three in the shoulder, two in the hand, one in the ankle [9]. All were reported in the English literature except two in the Japanese literature. NF in the hand is often mistaken for a soft tissue sarcoma, such as malignant fibrous histiocytoma or fibrosarcoma, resulting in ray amputation or unnecessary irradiation [10,11].

Several factors make the diagnosis of intra-articular NF difficult, which is why several distinctive features deserve further comment, to avoid misdiagnosis which can result in an incorrect treatment being applied. First, when compared to NF lesions arising in subcutaneous or intramuscular locations, the intra-articular location seems to have a notably longer clinical history. This may in part be secondary to the fact that the primary symptom was nonspecific joint pain with no palpable mass. Second, the initial X-rays were normal, the MRI findings were non-specific, and ultrasound was not very informative orienting the diagnosis towards osteoarthritis of the PIP joint. Indeed, MRI features of NF are often nonspecific and somewhat variable. In the largest MRI study of musculoskeletal NF, it typically appeared iso-intense to slightly hyperintense to muscle on T1-weighted images, hyperintense on T2-weighted images and homogenously enhanced after gadolinium administration [12]. Third, the tumor biopsy was suggestive of a fibrous tumor and was also non-specific, which could include the possibility of sarcoma, DT or FTS. The final diagnosis of intra-articular NF was made after complete excision of the tumor and its analysis with several IHC stains.

FTS is an uncommon benign tumor that almost always arises in the hands, typically within fibrotendinous tissue rather than in a joint. Pulitzer et al. [13] reported 32 cases of FTS. Most cases presented as a painless, firm and modular mass in the distal portion of an extremity. They concluded that at least some cases of FTS described as fasciitis-like actually represent examples of nodular fasciitis.

Extra-abdominal DTs are extremely rare in the hand. These tumors do not metastasize; however, they are potentially locally invasive and have extremely high local recurrence rates after surgical excision with reports of up to $78 \%$ recurrence, specifically in 
the hand. IHC characteristics of DT are helpful, as they do not have immunoreactivity for desmin, similar to NF [14], but have proliferating spindle cells on a collagenous background with positive nuclear beta-catenin expression and CD34, which is not found with NF.

In a recent study [15], the diagnostic utility of USP6 fluorescence in situ-hybridization (FISH) analysis in a subset of spindle-cell proliferations for the differential diagnosis of NF was evaluated. In morphologically definitive cases, FISH analysis for USP6 had a sensitivity of $86 \%$ and specificity of $100 \%$ for a diagnosis of NF. The positive predictive value was $100 \%$ and the negative predictive value $90 \%$. They concluded that USP6 FISH is a useful auxiliary test in cases where NF is a potential diagnostic consideration. In our clinical case, the diagnosis of intra-articular nodular fasciitis was confirmed step by step and after considering the IHC results together and specifically with the USP6 Break-Apart FISH probe which confirmed rearrangement in $28 \%$ of the cells analyzed.

The patient has had 6 follow-up visits over 12 months so far and is free of recurrence. This has been confirmed with follow-up MRI. He has almost a full range of finger movements after physical therapy and dynamic splinting, with the exception of a $15^{\circ}$ residual flexion deformity of the PIP joint in active extension.

\section{Conclusion}

Although NF of a finger is quite rare, it is important to keep in mind rarer pathologies such as intraarticular NF, especially with a history of trauma 10 years prior. NF should be included in the differential diagnosis of intraarticular masses discovered fortuitously even though it occurs in the finger joint. A biopsy is necessary before complete tumor excision. An experienced histologist must be part of the team to avoid a possible misdiagnosis of malignant fibrous histiocytoma or sarcoma, which can lead to unnecessary irradiation or finger amputation. We want to emphasize the importance of careful clinical and histological examination to avoid unnecessary aggressive surgery, since marginal excision will provide excellent results even in a case with a difficult location such the finger PIP joint. 
Disclosure of conflict of interest

None 


\section{References}

[1] Bernstein KE, Lattes R. Nodular (pseudosarcomatous) fasciitis, a non-recurrent lesion: clinicopathologic study of 134 cases. Cancer 1982;49:1668-78.

[2] Katz MA, Beredjiklian PK, Wirganowicz PZ. Nodular fasciitis of the hand: a case report. Clin Orthop Relat Res 2001;382:108-11.

[3] Rankin G, Kuschner SH, Gellman H. Nodular fasciitis: a rapidly growing tumor of the hand. J Hand Surg Am 1991;16:791-5.

[4] Konwaler BE, Keasbey L, Kaplan L. Subcutaneous pseudosarcomatous fibromatosis (fasciitis). Am J Clin Pathol 1955;25:241-52.

[5] Enzinger FM, Weiss SW. Soft tissue tumors, $3^{\text {rd }}$ ed. St Louis: CV Mosby; 1998.p 167-76.

[6] AL-Qattan MM, Arafah MM. Nodular fasciitis of the hand: excision preserving 'vital' structures. J Hand Surg Eur 2014;39:881-4.

[7] Dijoux P, Mesturoux L, Charissoux A, Pommepuy I, Layre B, Marcheix PS. Nodular fasciitis: case report and review of the literature. Chir Main 2013;32:341-44.

[8] Park JS, Park HB, Lee JS, Na JB. Nodular fasciitis with cortical erosion of the hand. Clin Orthop Surg 2012;4:98-101.

[9] Hornick JL, Fletcher CD. Intraarticular nodular fasciitis—a rare lesion: clinicopathologic analysis of a series. Am J Surg Pathol 2006;30:237-41.

[10] Yamamoto T, Nagira K, Noda M, Kurosaka M. Intra-articular fasciitis nodular. Arthroscopy 2001;17:E38.

[11] Shimizu S, Hashimoto H, Enjoji M. Nodular fasciitis: an analysis of 250 patients. Pathology 1984;16:161-6.

[12] Laffan EE, Ngan BY, Navarro OM. Pediatric soft-tissue tumors and pseudotumors : MR imaging features with pathologic correlation: part 2. Tumors of fibroblastic/myofibroblastic, so-called fibrohistiocytic, muscular, lymphomatous, neurogenic, hair matrix, and uncertain origin. Radiographics 2009;29:e36. 
[13] Pulitzer DR, Martin PC, Reed RJ. Fibroma of tendon sheath: A clinicopathologic study of 32 cases. Am J Surg Pathol 1989;13:472-79.

[14] Hasegawa T, Hirose T, Kudo E, Abe J, Hizawa K. Cytoskeletal characteristics of myofibroblasts in benign neoplastic and reactive fibroblastic lesions. Virchows Arch Pathol Anat Histopathol 1990;416:375-82.

[15] Shin C, Low I, Ng D, Oei P, Miles C, Symmans P. USP6 gene rearrangement in nodular fasciitis and histological mimics. Histopathology 2016;69:784-91. 


\section{Figure legends}

Fig. 1. Normal radiograph of the fourth finger (A). X-rays of the same finger, a few weeks later, showing well-defined cortical erosion at the base of the middle phalanx and the neck of the proximal phalanx of the PIP joint (white arrow) (B). Magnetic resonance imaging of the right ring finger showing a non-specific intra-articular well-circumscribed mass, with cortical erosion at the PIP joint, elevating the volar plate and the flexor tendon mechanism; T1weighted images have a low signal intensity $(C)$ and T2-weighted images have a homogenously high signal intensity (D).

Fig. 2. Intraoperative view of the non-encapsulated mass after a Bruner volar approach, pulleys removed, tendons dislocated, and complete detachment of the volar plate (A). View of the PIP joint and tumor after total resection, measuring $2.2 \times 1.5 \times 0.8 \mathrm{~cm}$ in size $(\mathrm{B})$.

Fig. 3. Microscopic images of the intra-articular nodular fasciitis specimen from the marginal excision. Medium-power view of NF showing proliferation of non-atypical fusiform cells with background of numerous extravasated erythrocytes, hemosiderin deposition, and lymphocytic inflammation (A). High-power view of NF showing myofibroblastic-like spindle cells without nuclear atypia or mitotic activity (B). 

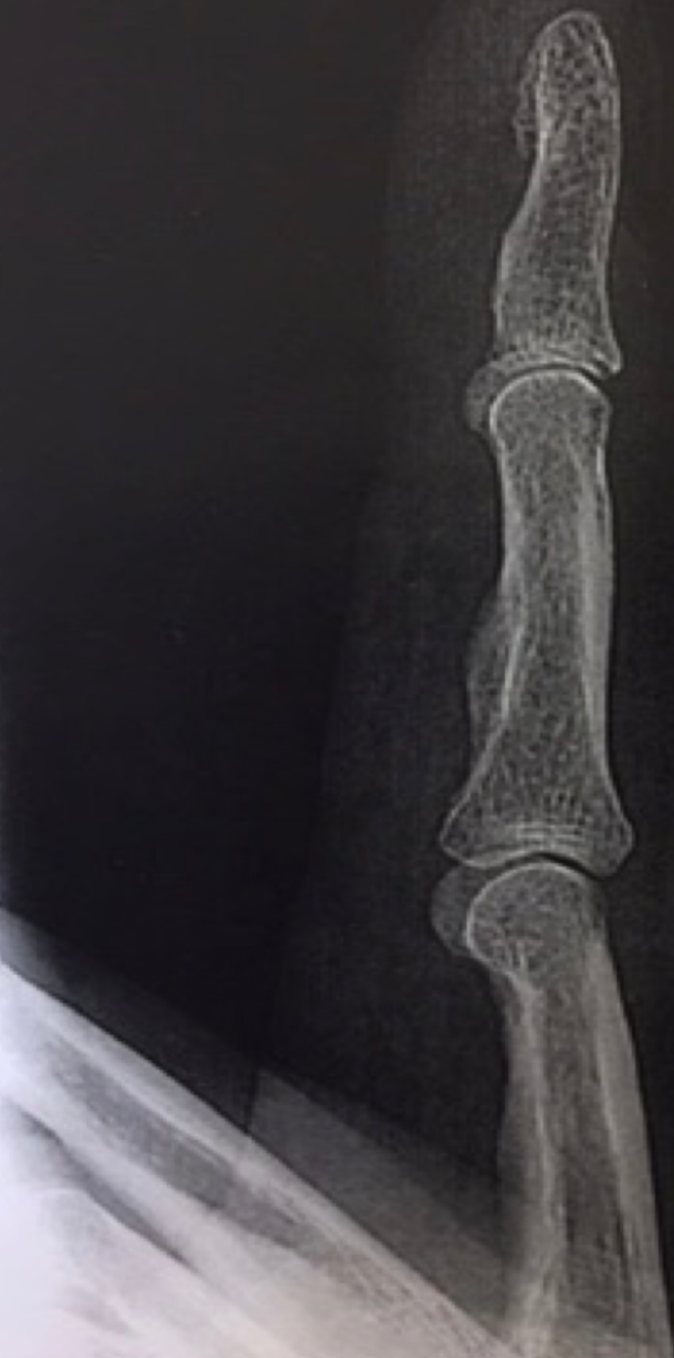
$4 e$

\section{DROIT}




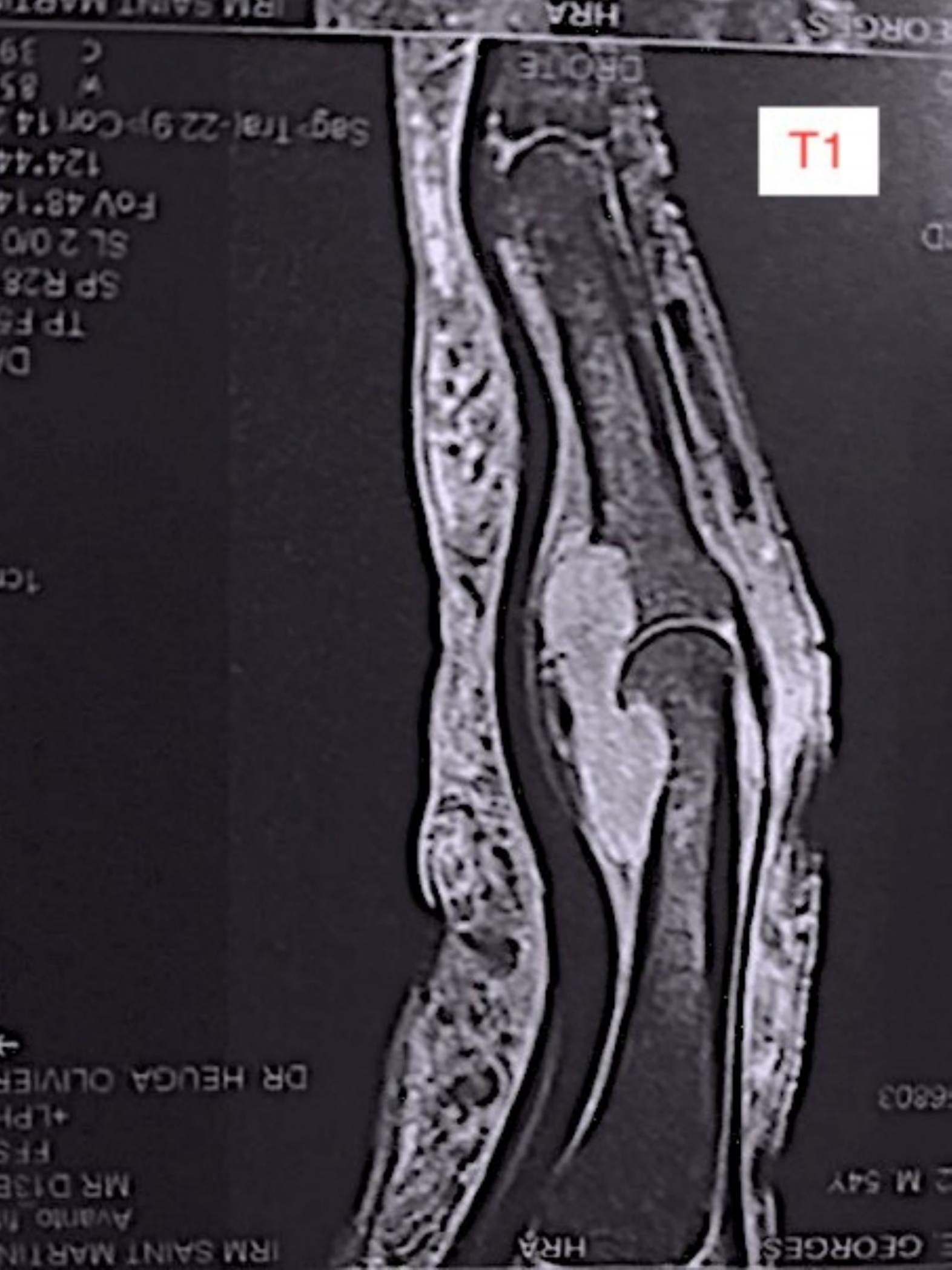




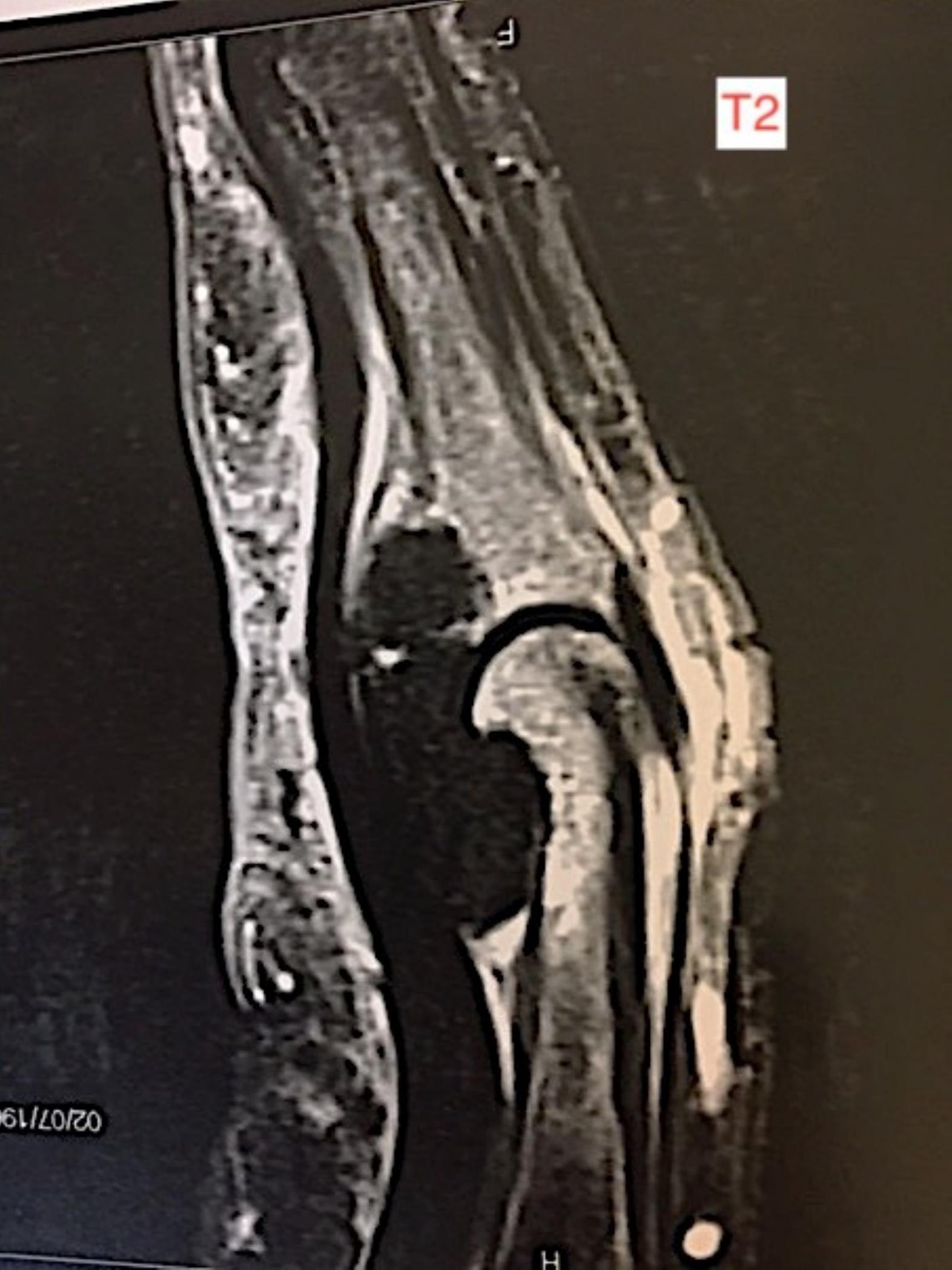




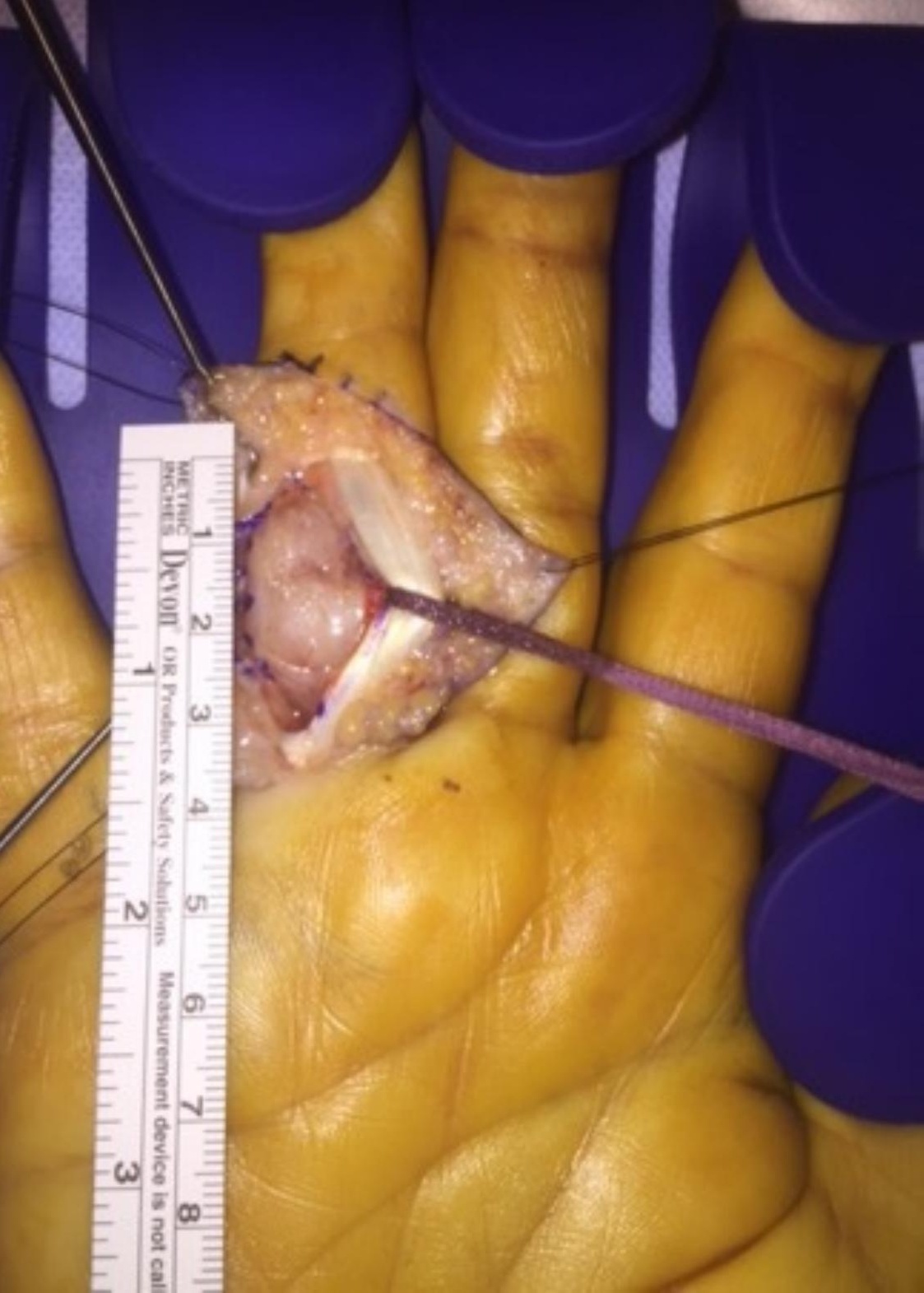





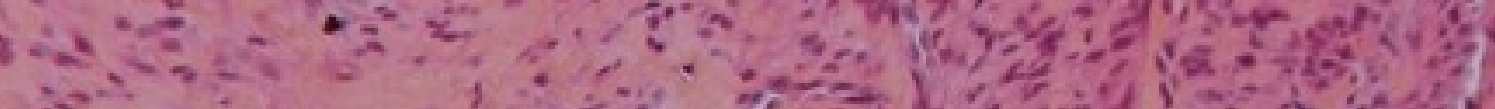

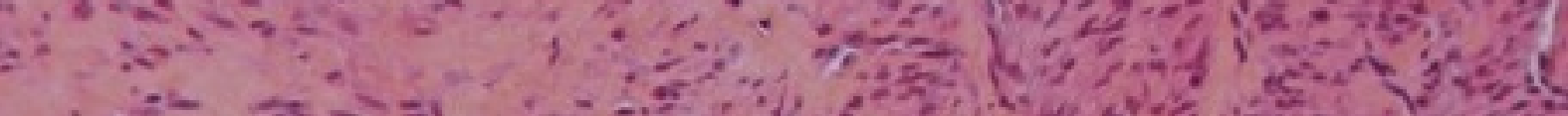

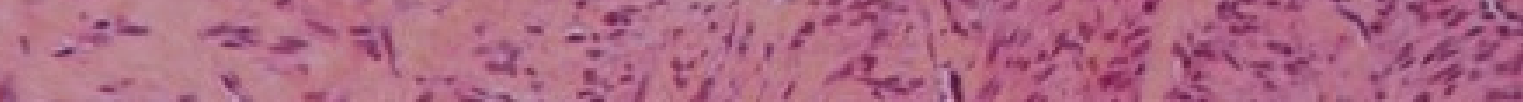

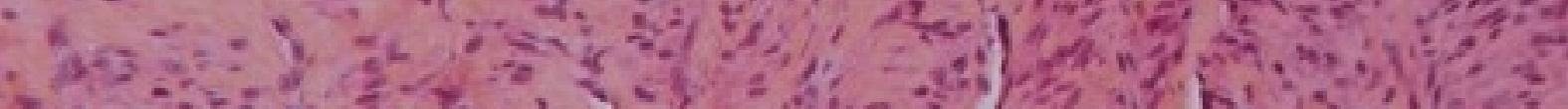

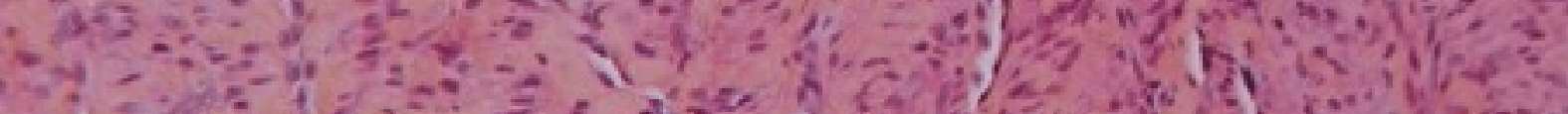
a 3 ty

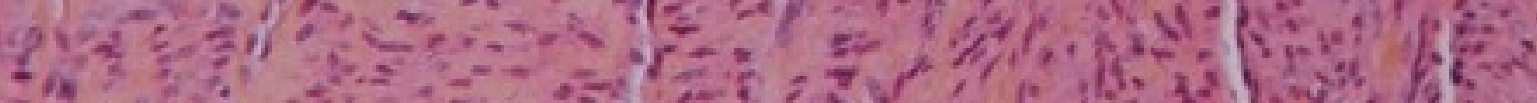

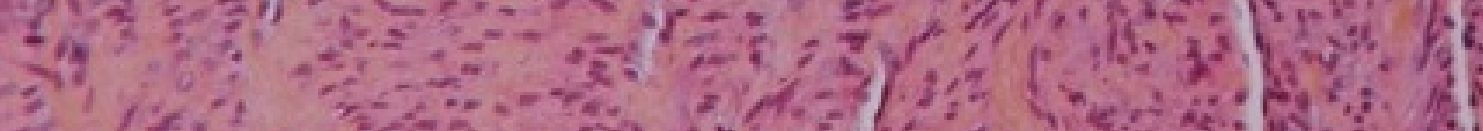

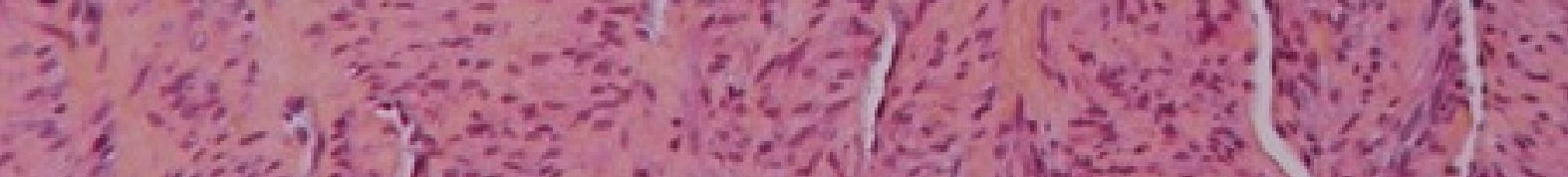

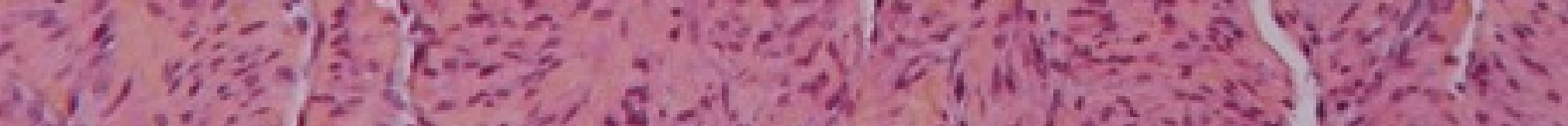

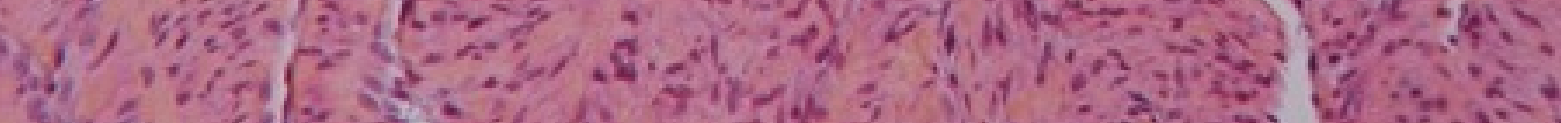

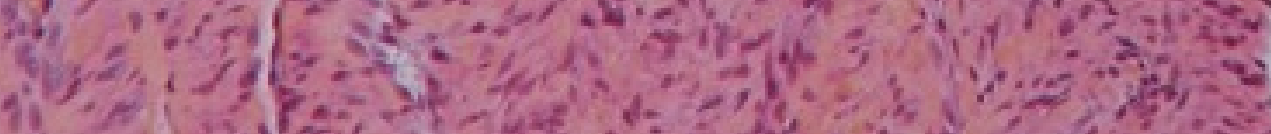

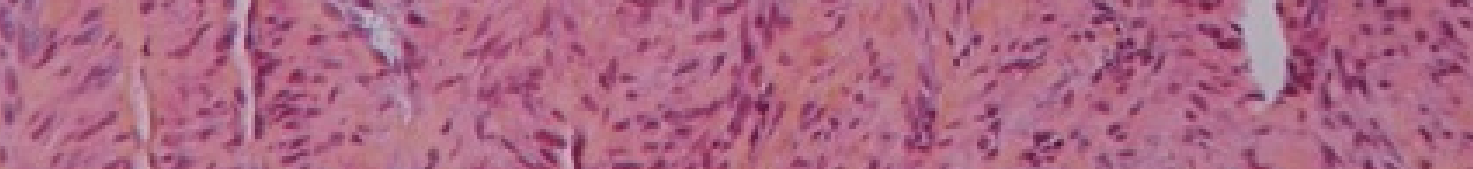

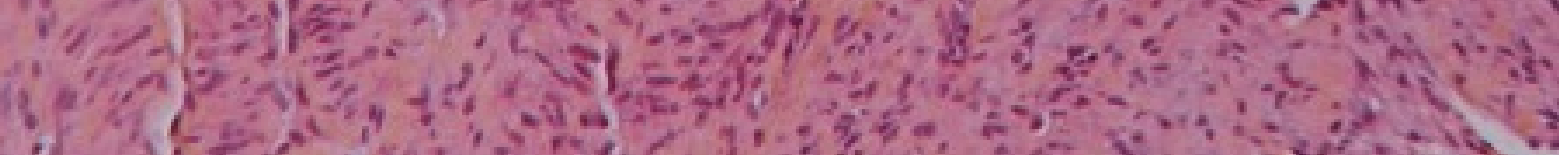
$25=0$ y

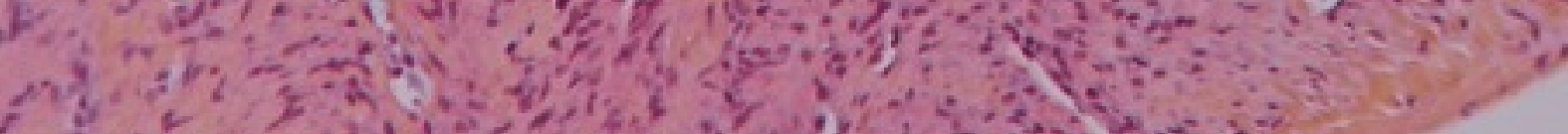

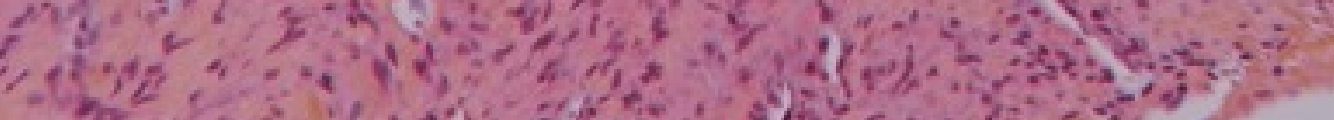

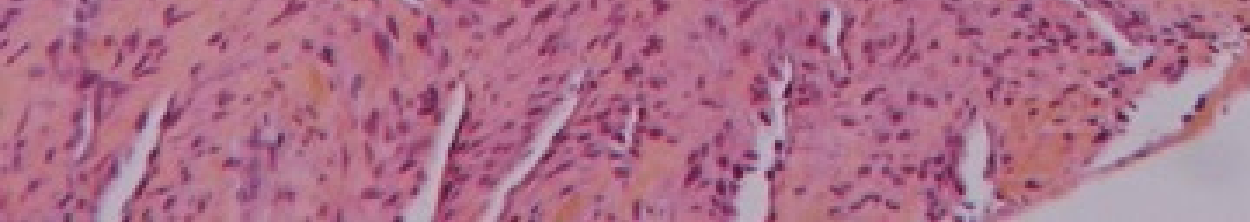


2.

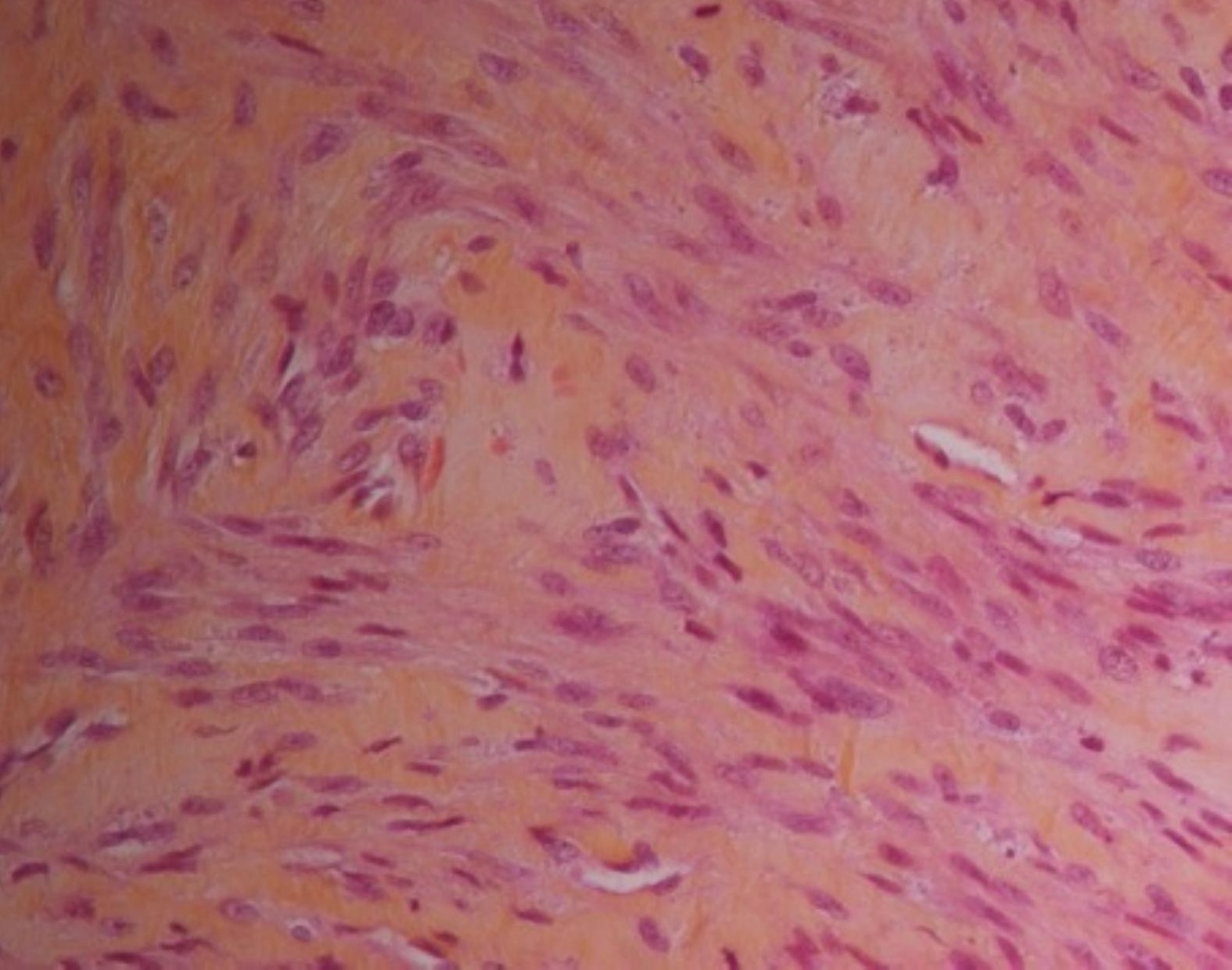

